\title{
Pesticide-Soil Interaction
}

\author{
Rita Földényi ${ }^{1}$, Imre Czinkota ${ }^{2}$ and László Tolner² \\ ${ }^{1}$ Institute of Environmental Sciences, University of Pannonia, Veszprém, \\ ${ }^{2}$ Department for Soil Science and Agricultural Chemistry, Szent István University, Gödöllö
}

Hungary

\section{Introduction}

Modern pesticides have to fulfill two requirements: they have to control weeds, pests, diseases, etc. while not to load the environment. These agents should put out their plant protective effect before their degradation. It results in an apparent contradiction because the stable chemicals are able to become environmental contaminants concentrated mostly in the soil. The retention of the pesticides in the soil is important otherwise they can reach the groundwater by leaching. It means that the vertical mobility of these compounds is strongly correlated with their adsorption behavior. If we want to predict the leachability of a pesticide the first step is the investigation of its chemical stability under the given conditions (soil type, $\mathrm{pH}$ etc). It is followed by the second step being the study of its adsorption on the soil.

\section{The degradation of pesticides in the soil}

Pesticide breakdown in the soil is classified as chemical and biological processes influenced by physical factors leading to very complicated pathways. The decomposition is chemical when it takes place in the absence of living organisms. In this case the reaction is activated by thermal, photochemical, radiochemical, electrochemical factors as well as by the interaction with the soil. Photochemical degradation occurs at the soil surface where the energy of sunlight can be absorbed either directly by the pesticide or indirectly by soil components working as photocatalyst. Since atmospheric ozone absorbs solar radiation below $290 \mathrm{~nm}$ only chemicals that absorb above this wavelength can be decomposed directly by sunlight. The interaction with the soil means either the catalytic effect of its constituents (e.g. clay minerals) or reactions with its organic matter content (e.g. redox reactions).

In the presence of living organisms biological degradation can take place. In these pathways mainly the enzyme system of microorganisms (bacteria, algae, fungi etc.) works as biocatalyst. Also other species can contribute to the transformation of the parent compound. For example the roots of plants produce fluids which assist the decomposition.

The microorganisms in the soil are either pesticide susceptible or not. In the latter case they will be killed by the compound and no degradation occurs while only a part of the resistant communities can degrade the pesticide (Pierzynski et. al., 1994). The non-biodegradable compounds are persistent and their presence in the soil results in contamination. 
The most notorious example for the persistent pesticides is DDT being one of the chlorinated hydrocarbon type insecticides. This compound and their degradation products (DDD, DDE) can be detected in the soil and sediment even after about 30 year of the contamination (Skibniewska et.al., 2003).

As the soil is contaminated in highest amounts by herbicides present study is focused on the fate of different types of these agents in the soil.

The degradation of pesticides takes place in most cases either on (by oxygen, light) or near to the soil surface (by oxygen, microbial activity). For this reason the residence time of the agent in this active layer is a determinant factor. The conditions in deeper active layer are considered mainly anoxic. It is represented by the laboratory experiments (aeration just during the sampling, $25^{\circ} \mathrm{C}$, and natural light in the lab) in the following sections which are numbered according to the type of the herbicide investigated.

\subsection{Chloroacetanilide type herbicides (acetochlor and propisochlor)}

The chloroacetanilide type herbicides acetochlor and propisochlor (Fig. 1) are widely used in the world. This is the same in Hungary where they were produced in high amounts until the beginning of the XXI. century. In the literature more information can be found about the decomposition of the active ingredient $\mathbf{1}$ than about $\mathbf{2}$ which is an original Hungarian product.

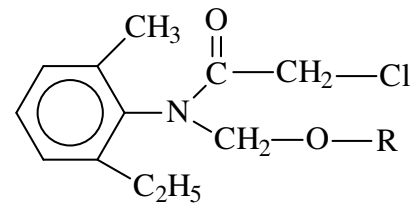

1. $\mathrm{R}=$ ethyl

2. $\mathrm{R}=$ isopropyl

Fig. 1. The structure of acetochlor (1) and propisochlor (2)

Chloroacetanilides are stable at environmentally relevant $\mathrm{pH}$ and temperature in buffer solutions. In the soil, plants and animals more than 30 degradation products of these herbicides have been already identified. Two different dechlorination reactions of acetochlor have been proved in the soil: a. hydrolysis, b. glutathione conjugation (Roberts, 1998a). Both pathways are very important in the detoxification of this compound.

The aim of the study presented here was to check the stability of the compounds $\mathbf{1}$ and $\mathbf{2}$ in different types of soils under the conditions detailed above. The decay of these herbicides was followed in the liquid phase $(\mathrm{pH}=7)$ of the suspension made from soil : buffer= $1: 10$ ratio. Figure 2 shows that both compounds proved to be rather stable but the degradation of acetochlor (Fig. 2 a.) seemed to be slightly slower than that of propisochlor (Fig. 2 b.). Comparing the soils the decomposition was the fastest in the presence of chernozem having the highest organic carbon content $(25.18 \mathrm{mg} \mathrm{TOC} / \mathrm{g})$. In the case of propisochlor the order of the breakdown rates follows the TOC values of the soils, which can be seen on Fig $2 \mathrm{~b}$. The decay of acetochlor proved to be rather similar in the soils having lower organic carbon content (brown forest and sandy soils).

These results emphasize that the degradation of the chloroacetanilide type compounds need the presence of soil organic matter which is the living space of different species. It means that the degradation is governed by biological processes. 


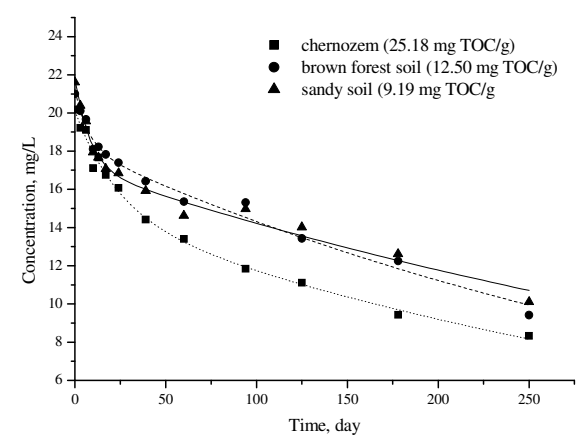

a. Acetochlor degradation, $\mathrm{pH}=7$

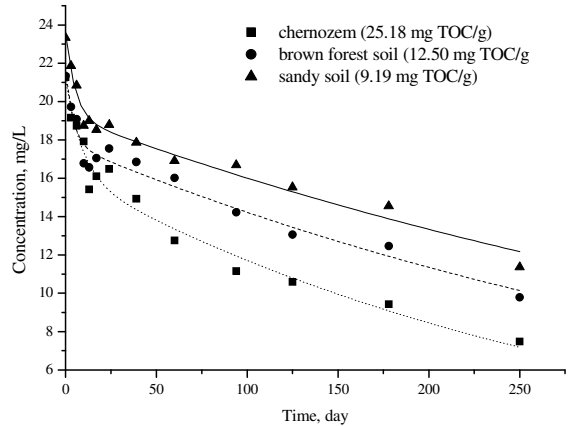

b. Propisochlor degradation, $\mathrm{pH}=7$

Fig. 2. Degradation of acetochlor and propisochlor in the presence of different soils

Field measurements in China soils resulted in $t_{1 / 2} \approx 5$ days for propisochlor (Wang et. al., 2007). In experiments carried out with compound $\mathbf{1}$ and $\mathbf{2}$ in soils of temperate zone relatively long half-life time was determined under field conditions: for acetochlor approx. 17 days while for propisochlor approx. 10 days (Ferenczi, 1998). According to these results it can be pointed out that the climate (temperature, moisture, $\mathrm{pH}$ of the soil etc.) significantly influences the degradation of these compounds.

We must mention that first order kinetic is commonly used for pesticide decomposition even in the case when the fitting is not the best at the well-known linearization method.

$$
c=c_{1} \cdot e^{-k_{1} \cdot t_{1}}+c_{2} \cdot e^{-k_{2} \cdot t_{2}}
$$

$c_{1}$ and $c_{2}$ : initial concentrations;

$k_{1}$ and $k_{2}$ : rate constants;

$t_{1}$ and $t_{2}$ : reaction time in the two parallel steps.

In our case neither the equation of the simple first order nor that of second order kinetic reaction resulted in relatively good fitting ( $R^{2}$ should be at least ca. 0.9). It suggests a complex degradation pathway that cannot be described by one process alone. The application of two parallel reactions with first order kinetic (1) resulted in quite good $R^{2}$ value (Table 1$)$. The half life time $\left(t_{i(1 / 2)}\right)$ was calculated in both steps $(i=1,2)$ by equation $(2)$ as it is generally calculated in first-order kinetic reactions.

$$
t_{i(1 / 2)}=\frac{\ln 2}{k_{i}}
$$

where $k_{i}$ means the rate constants in step 1 and 2 .

According to the calculated $t_{i(1 / 2)}$ of these two reactions it can be pointed out that one of the reactions (see $t_{1(1 / 2)}$ in Table 1 ) is much faster than the other (see $t_{2(1 / 2)}$ in Table 1). Regarding the total degradation rate these data are in accordance with the explanations given for Fig. 2., however, the acetochlor decomposition on brown forest soil is faster than it was understand on the basis of Fig. 2 a.

Our results and the field experiments carried out by other authors (Ferenczi, 1998; Konda \& Pasztor, 2001; Wang et. al., 2007) indicate that the organic matter content of the soil is 
essential in the breakdown of chloroacetanilides but the composition of this organic matter and also other factors can influence this process.

\begin{tabular}{|l|l|l|l|l|l|l|}
\hline Soil & \multicolumn{2}{l}{ Chernozem } & \multicolumn{3}{l|}{ Brown forest } & \multicolumn{2}{l|}{ Sandy soil } \\
\hline Compound & $\mathbf{1}$ & $\mathbf{2}$ & $\mathbf{1}$ & $\mathbf{2}$ & $\mathbf{1}$ & $\mathbf{2}$ \\
\hline Parameters & & & & & & \\
\hline$k_{1}(1 /$ day $)$ & 0.0426 & 0.04426 & 0.13133 & 0.24598 & 0.11934 & 0.18978 \\
\hline$t_{1(1 / 2)}$ (day) & 16.27 & 15.66 & 5.28 & 2.82 & 5.81 & 3.65 \\
\hline$k_{2}(1 /$ day) & 0.00238 & 0.00273 & 0.00243 & 0.00225 & 0.00189 & 0.00183 \\
\hline$t_{2(1 / 2)}$ (day) & 291.24 & 253.90 & 285.25 & 308.07 & 366.74 & 378.77 \\
\hline$R^{2}$ & 0.9940 & 0.9704 & 0.9874 & 0.9684 & 0.9848 & 0.9774 \\
\hline
\end{tabular}

Table 1. Calculated parameters of equation (1) for chloroacetanilide degradation<smiles>CC(C)N(C(=O)CCl)c1ccccc1</smiles>

3<smiles>CCOCN(C(=O)CO)c1c(C)cccc1CC</smiles>

4

(2-chloro-[N-(1-methylethyl)-N-phenyl]acetamide)

(2-hydroxy-[N-(2-ethyl-6-methyl)-phenyl$\mathrm{N}-($ alkoxy-methyl)]-acetamide)

Fig. 3. Chloroacetanilide degradation products identified in the soil

The types of degradation products (Fig. 3) identified in the soil at the end of the experiments support the idea of two ways of pesticide breakdown. (Of course the decomposition pathway can be much more complicated.) After appropriate preparation of the samples compound 3 (m/z: 211, M+) was determined by GC-MS in the case of both chloroacetanilides. The structure of this acetamide indicates an isomerisation reaction. Product 4 determined by DRIFT FT-IR spectroscopy is the result of the hydrolysis of acetochlor.

Isomerization generally needs catalyst that is likely an enzyme of any microorganism in the soil. The hydrolysis can occur in any aquatic medium even under sterile conditions but it can be faster when living organisms are present.

\subsection{Urea type herbicides (isoproturon)}

The urea type compounds are herbicides with intermediate persistence in aerobic soils. Enhanced rates of their degradation have not been observed even under anaerobic conditions. Isoproturon (see compound $\mathbf{5}$ in Fig. 5) is applied nowadays most frequently in combination with other active ingredients but even at the end of the XX. century its consume was about 500 tons/year in Europe. Since the information about the decomposition of this compound is rather incomplete (Roberts, 1998b) the present section focuses on this representative of urea type herbicides.

The decay of isoproturon was compared in different buffered solutions ( $\mathrm{pH}=5, \mathrm{pH}=7, \mathrm{pH}=8)$ in the absence as well as in the presence of soils. This active ingredient proved to be a rather persistent compound because its concentration in the buffer decreased only by 5.5-12\% until 
the 350th days of the study. It can be pointed out that the decomposition of isoproturon hardly depends on $\mathrm{pH}$ but it is faster in the presence of the soils. Comparing the degradation in the presence of different soils at neutral $\mathrm{pH}$ the experience was similar as it was found in the case of chloroacetanilide type herbicides: the organic content of the soil plays leading role in the decay of the compound but also other factors affect the breakdown (Fig. 4, Table 2).

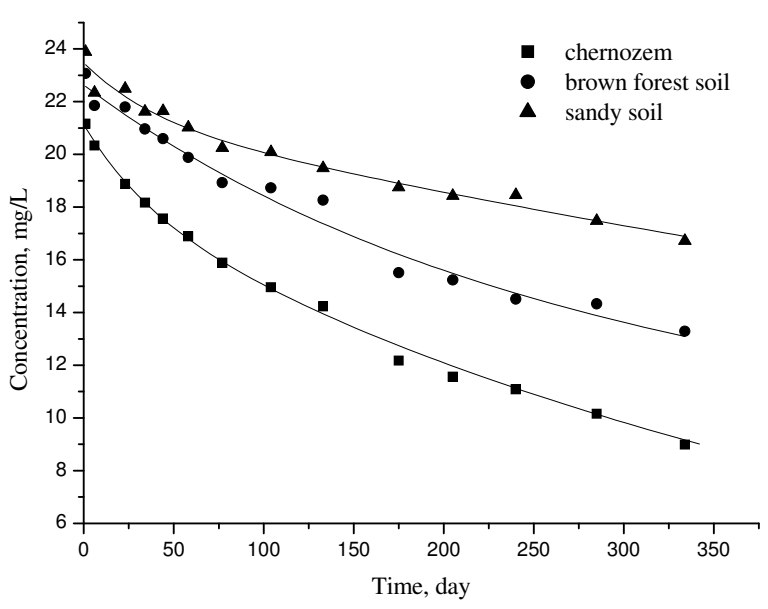

Fig. 4. Degradation of isoproturon in the presence of different soils, $\mathrm{pH}=7$

The fitting according to equation (1) and the determination of the half-life times (Eq. (2)) were carried out as it was described for chloroacetanilide herbicides (Section 2.1.). Calculated parameters show that both steps as well as the total reaction were the slowest in the presence of brown forest soil.

\begin{tabular}{|c|c|c|c|}
\hline \multirow{2}{*}{ Parameters } & \multicolumn{3}{|c|}{ Soil } \\
\hline & Chernozem & Brown forest & Sandy soil \\
\hline$k_{1}$ (1/day) & 0.02669 & 0.0049 & 0.02517 \\
\hline$t_{1(1 / 2)}$ (day) & 25.97 & 141.46 & 27.54 \\
\hline$k_{2}$ (1/day) & 0.00206 & 0.00057 & 0.0007 \\
\hline$t_{2(1 / 2)}$ (day) & 336.48 & 1216.05 & 990.21 \\
\hline$R^{2}$ & 0.9980 & 0.9817 & 0.9774 \\
\hline
\end{tabular}

Table 2. Calculated parameters of equation (1) for isoproturon degradation

The investigation of the degradation products, however, indicates other type of reactions, too. According to GC-MS the liquid phase $(\mathrm{pH}=7)$ over chernozem contained two degradation products (6 and 7 in Fig. 5). 6 was identified earlier in aquatic solution using UV light ( $\mathrm{pH}>7$ ) as well as in soil while 7 formed only under UV radiation at $\mathrm{pH}=7$ (Roberts, 1998c). 


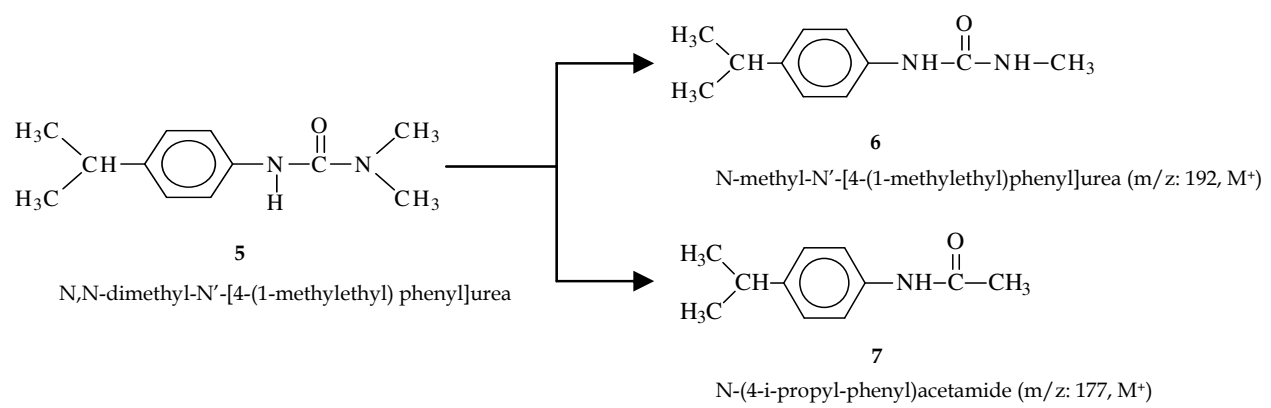

Fig. 5. Isoproturon (5) degradation regarding the products $(6,7)$ of photo catalytic reaction

This refers to the photosensitization effect of humic substances in the decomposition of isoproturon. This conclusion is in accordance with the results of Gerecke et al. who observed the photocatalytic role of DOM (Gerecke et. al., 2001) in the degradation of phenylurea herbicides. This process can work on the soil surface after application of the herbicide, and in surface waters in case of their pollution by this compound.

\subsection{Sulfonyl urea type herbicides}

The sulfonyl urea type herbicides (8) are relatively young compounds among the pesticides. Their stability and other chemical as well as physical properties (e.g. solubility) strongly depend on their structure. This is in correlation with the dissociable proton (signed with red color in Fig. 6) that results in weak acidic character of these compounds (Roberts, 1998d).

The importance of this reaction is emphasized by $\mathrm{pK}_{\mathrm{a}}$ values. It can be seen e.g. in the comparison of two sulfonyl urea type compounds having just one difference: tribenuron methyl (9 in Fig. 8) has a methyl substitution on $\mathrm{N}^{2}$ while metsulfuron methyl (10 in Fig. 9) has a proton in this position. The $\mathrm{pK}_{\mathrm{a}}$ values of compounds $\mathbf{9}$ and $\mathbf{1 0}$ are 5.0 and 3.3, respectively. For this reason the investigations were focused on the comparison of degradation of these two compounds on two different soils: on the rather basic chernozem $(\mathrm{pH}=8.34)$ and on the acidic brown forest $(\mathrm{pH}=5.92)$ soils. The aquatic medium equilibrated with the surface was buffered and had the same $\mathrm{pH}$ like the soil.

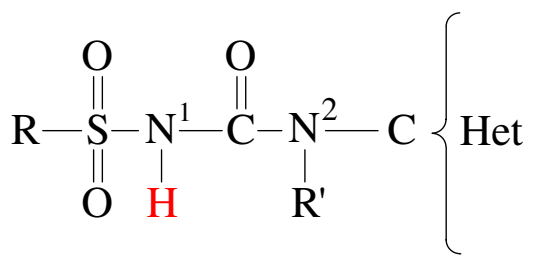

8

$\mathrm{R}=\mathrm{Me}$, substituted $\mathrm{Ph}$, substituted heterocycle; $\mathrm{C}\left\{\mathrm{Het}=\right.$ substituted pyrimidine or triazine, $\mathrm{R}^{\prime}=\mathrm{H}, \mathrm{Me}$

Fig. 6. General structure of sulfonylurea herbicides

As it is found the tribenuron methyl is relatively stable over chernozem but not over brown forest soil (Fig. 7). The reaction rates differ much more significantly than in the other cases when the $\mathrm{pH}$ was the same and only the TOC content of the soils varied. 
The fitting of the measured data for chernozem was carried out according to zero order kinetic being characteristic in heterogeneous system, and it is described with a simple linear equation.

\begin{tabular}{|c|c|c|c|c|c|c|}
\hline Soil & \multirow{2}{*}{\multicolumn{2}{|c|}{$\begin{array}{c}\text { Chernozem } \\
c=-k t+c_{0}\end{array}$}} & \multicolumn{4}{|c|}{ Brown forest } \\
\hline Equation & & & $\ln (c / c$ & $=-k t$ & $c=c_{1} \cdot e^{-k} t_{1}$ & $c_{2} \cdot e^{-k_{2} t_{2}}$ \\
\hline \multirow{4}{*}{ Parameters } & \multirow{2}{*}{$k$ (1/day) } & \multirow{2}{*}{0.2207} & \multirow{2}{*}{$k$ (1/day) } & \multirow{2}{*}{0.2343} & $k_{1}$ (1/day) & 0.2080 \\
\hline & & & & & $t_{1(1 / 2)}$ (day) & 3.33 \\
\hline & \multirow{2}{*}{$t_{1 / 2}$ (day) } & \multirow{2}{*}{102.70} & \multirow{2}{*}{$t_{1 / 2}$ (day) } & \multirow{2}{*}{2.96} & $k_{2}$ (1/day) & 3374.74 \\
\hline & & & & & $t_{2(1 / 2)}$ (day) & 0.0002 \\
\hline$R^{2}$ & \multicolumn{2}{|l|}{0.9887} & \multicolumn{2}{|l|}{0.9934} & \multicolumn{2}{|l|}{0.9971} \\
\hline
\end{tabular}

Table 3. Fitting parameters of tribenuron methyl decomposition supposing different kinetic

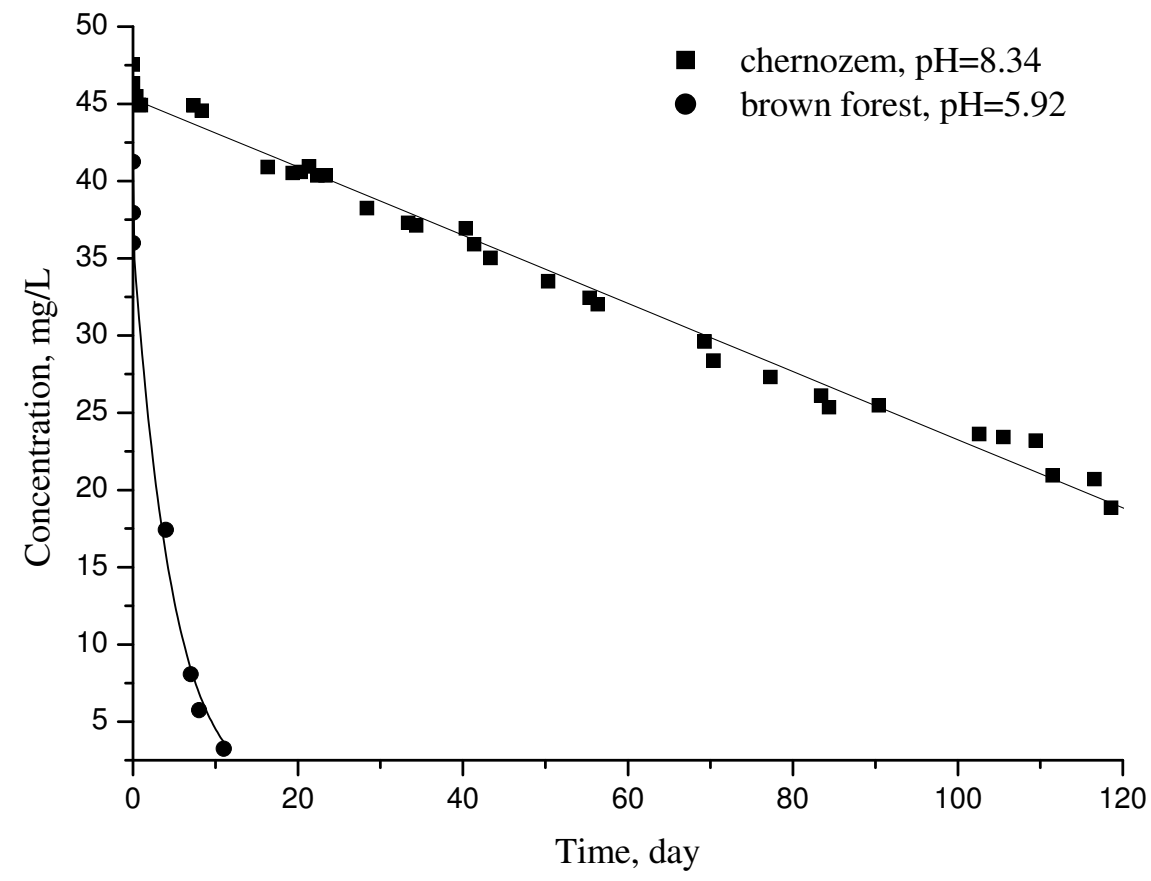

Fig. 7. Degradation of tribenuron methyl in the presence of two different soils 
<smiles></smiles>

9

methyl-2-[N-(4-methoxy-6-methyl-1,3,5triazin-2-yl)-3-(methyl-ureido)-sulfonyl]benzoate (m: $395 \mathrm{~g} / \mathrm{mol}$ )

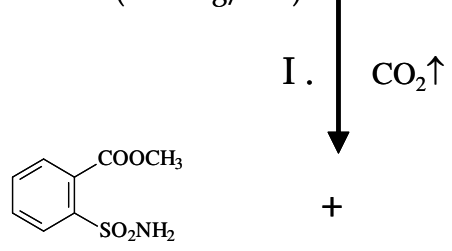

11

methyl-2-(amino-sulfonyl)-benzoate (m/z: 215, $\left.\mathrm{M}^{+}\right)$

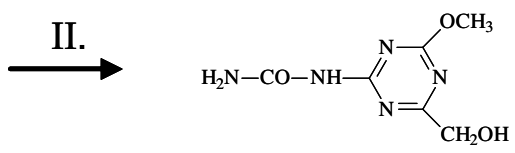

13

N-[4-methoxy-6-(hydroxy-methyl)-1,3,5-triazin2-yl]-urea (m/z: 200, $\left.\mathrm{MH}^{+}\right)$

\section{on brown forest and chernozem} soils<smiles>CNc1nc(C)nc(OC)n1</smiles>

12

4-methoxy-6-methyl-2-(amino-methyl)-1,3,5-triazin $\left(\mathrm{m} / \mathrm{z}: 154, \mathrm{M}^{+}\right)$

on brown forest soil

Fig. 8. The scheme of tribenuron methyl (9) decomposition concerning the identified degradation products

In the case of brown forest soil the first order kinetic was applied for the fitting when either one (using linearization method) or two parallel reactions (Eq. (1)) were supposed. Every counted parameter is summarized in Table 3 where the $R^{2}$ values are rather good but regarding the brown forest soil the fitting for two parallel reactions was even better than only for one step. According to these results it has to be emphasized that the reaction pathways are always much more complicated than they are commonly simplified.

The degradation of metsulfuron methyl (10 in Fig. 9) followed zero order kinetic. This compound proved to be persistent under the laboratory conditions because its half life time was over chernozem 500, and over brown forest soil 515 days indicating that the $\mathrm{pH}$ did not influenced its decomposition. Since the decay rate of this compound over the soils did not show significant difference from that in the buffer solution it seems that the degradation of this herbicide is slightly assisted by organic matter of the soils used in this experiment.

The degradation products were investigated after extraction of the equilibrated solution as well as of the soil and were compared to the blanks studied without soil. According to GC-MS spectra both extracts (obtained from the solution or from the soil) had the same components. In the case of the acidic sample (brown forest soil investigations) the identified degradation products of tribenuron methyl (9) were: 11, 12 and 13 (Fig. 8). The blank sample contained $\mathbf{1 1}$ and $\mathbf{1 2}$ indicating the hydrolytic cleavage of the sulfonylurea linkage (see I. in Fig. 8). It can take place even without the presence of the soil. $\mathrm{CO}_{2}$ is produced during this reaction which is often hundreds of times faster under acidic conditions (Roberts, 1998d). 
<smiles>COc1nc(C)nc(NC(=O)NOc2ccccc2C(=O)O)n1</smiles>

methyl-2-[N-(4-methoxy-6-methyl-1,3,5-triazin2-yl)-ureido-sulfonyl]-benzoate $(\mathrm{m}: 381 \mathrm{~g} / \mathrm{mol})$

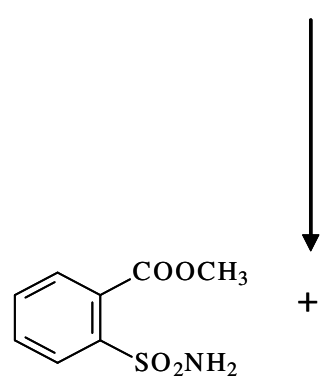

11

methyl-2-(amino-sulfonyl)benzoate, $\left(\mathrm{m} / \mathrm{z}: 215, \mathrm{M}^{+}\right)$<smiles>COc1nc(C)nc(N)n1</smiles>

14

4-methoxy-6-methyl-2-amino1,3,5-triazin, (m/z: 140, $\left.\mathrm{M}^{+}\right)$

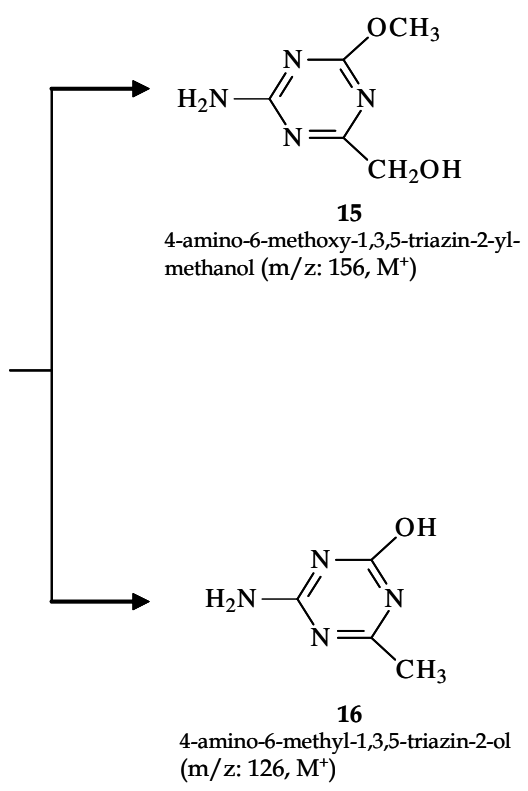

Fig. 9. The scheme of metsulfuron methyl (10) decomposition concerning the identified degradation products

Extracts obtained from the chernozem investigations contained only $\mathbf{1 3}$ being a newly determined compound and no hydrolysis products were identified. This result suggests another decomposition mechanism (II.) attributable to the presence of the soil (e.g. humic substances, living organisms). Reaction I. proved in the presence of brown forest soil does not need any organic matter.

Investigations regarding the metsulfuron methyl degradation also resulted in hydrolytic cleavage products of the sulfonylurea linkage (see compounds 11, 14 in Fig. 9). The other degradation products $(\mathbf{1 5}, \mathbf{1 6}$ Fig. 9) were found only in the presence of the chernozem soil. These compounds indicate, that the organic matter did not increase the decay rate of metsulfuron methyl, however, it must have a special role in the decomposition.

\section{Pesticide sorption on the soil}

The sorption on the solid matrix of the soil is one of the most important processes which control transport, persistence, bioavailability and degradation of organic pesticides on soil. Many theories and models have been presented in the literature to describe the different types of sorption isotherms. The most commonly used adsorption isotherm equations for organic contaminants on soil are the Langmuir and the Freundlich isotherms. 
The soil as an adsorbent has various active sites leading to rather complicated adsorption mechanisms with the environmental pollutants like pesticides.

\subsection{Adsorption described by multi-step isotherm}

Bioavailability and environmental transport of pesticides in soil-water system are controlled by their adsorption properties. The extent of adsorption is one of the most important chemical parameter entering into the differential material balance equations of the hydrogeochemical transport models (Weber et al., 1991; Klein et al., 1997; Kovács, 1998). Equilibrium distribution of the studied solute is usually described by some specific form of the general equation (3):

$$
q=f(c)
$$

where $q$ is the amount of adsorbed solute per gram of sorbent and $c$ is the concentration of the solute in the equilibrium solution phase. Depending on the type of interactions contributing to the adsorption mechanism equation (3) can take on various specific forms. The non-classical nature of the adsorption of hydrophobic organic compounds by soils is taken into consideration in the so-called distributed reactivity model developed by Weber et al. (1992). Soil is basically considered here as a composite material containing inorganic and two types of organic constituents each characterized by its local sorption isotherm. Adsorption of organic contaminants on the exposed surface of the inorganic mineral components is described by the Langmuir isotherm. One part of the soil organic constituent is the geologically older (hard) organic fraction (kerogen, coals etc.) that presents a relatively hydrophobic surface upon which the retention of the contaminant is described by the Freundlich isotherm. The other type of organic soil component is represented by the evolutionary immature (soft) material (humic substances etc.) which is more likely to function as partitioning media upon which the retention of solute is characterized by a linear Henry type of isotherm equation. The distributed reactivity model accommodates these linear and non-linear local adsorption isotherms and the total sorption is approximated as the sum of the isotherms (Weber et al., 1992):

$$
q_{r}=\sum_{i=1}^{m} x_{i} \cdot q_{i}
$$

where $q_{r}$ is the overall solid-phase concentration of the solute, $q_{i}$ is the part of $q_{r}$ attributable to the $i$ th of $m$ individual local isotherms (in this case it is expressed per unit mass of the solid-phase component responsible for the $i$ th local reaction) and $x_{i}$ is the mass fraction of that solid-phase component. Different types of isotherms suggested for the description of the adsorption of hydrophobic organic contaminant on soils were summarized and discussed by several recent reviews (Voice \& Weber, 1983; Weber et al., 1983; Samiullah, 1990; McBride, 1994; Wolt, 1994; Mader et al., 1997; Carmo et al., 2000). Two-step isotherms were reported for the adsorption of the tenside sodium dodecylsulfate on graphitized carbon (Zettlemoyer \& Micale, 1971). At low concentrations the tenside is adsorbed at some equilibrium orientation when a longer length of the hydrocarbon chain is in contact with the surface. At higher concentrations, however, the orientation changes to a new equilibrium position leading to the enhancement of adsorption shown as a second plateau of the isotherm. Systematic study of the adsorption of different surfactants by Clunie \& Ingram (1983) and Jönsson et al. (1998a) also revealed the occurrence of two-step isotherms.

Sodium dodecyl sulfate (SDS) is a widely used and also well investigated anionic surfactant. 


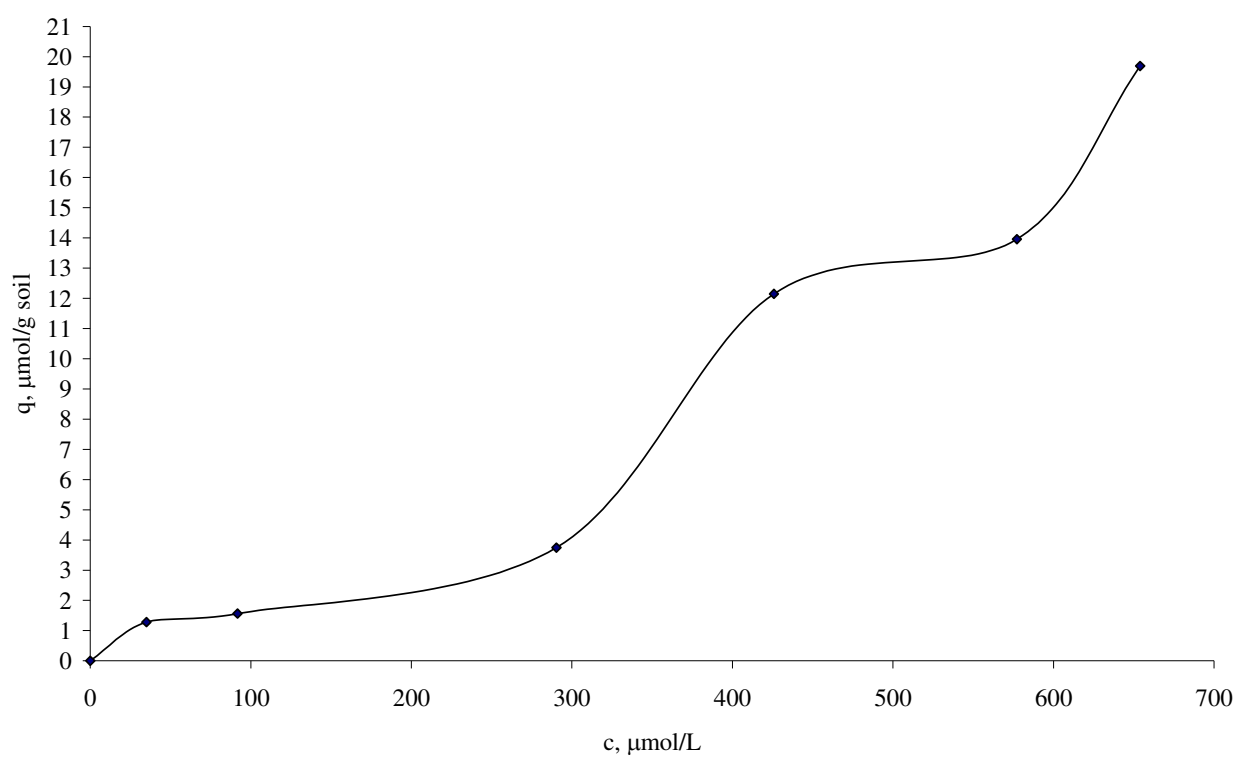

Fig. 10. Adsorption of SDS on sandy soil

Since it can be used even in pesticide formulation the adsorption of SDS was carried out on sandy soil (see Fig. 10). The isotherm has three steps indicating the micelle formation of the molecules either on the surface or in the solution. The critical micelle concentration $(\mathrm{cmc})$ of this surfactant is $830 \mu \mathrm{mol} / \mathrm{L}$ at $20{ }^{\circ} \mathrm{C}$ (Jönsson et. al., 1998b). It can be seen on Fig. 10 if the equilibrium concentration is less than $100 \mu \mathrm{mol} / \mathrm{L}$ the curve forms a Langmuir-type isotherm which suggests the filling of active sites by single molecules. When the specific adsorbed amount $(q)$ is $1.6 \mu \mathrm{mol} / \mathrm{g}$ soil the surface is covered by single SDS molecules (maximal coverage: $q_{T}$ ). In the solution of this surfactant the micelle formation starts above $800 \mu \mathrm{mol} / \mathrm{L}$, however, the molecules adsorbed already on the surface assist the formation of associates even at lower equilibrium concentration values. The second step of the isotherm having $14 \mu \mathrm{mol} / \mathrm{g}$ soil maximal adsorption capacity $\left(q_{T}\right)$ means if the ratio of the $q_{T}$ values of the second and first steps (14/1.6) is calculated, its result is 9 . This allows us to suppose that 9 levels of SDS molecules can cover the surface.

Our experiments with the chloroacetanilide as well as with other type of herbicides usually resulted in similar isotherms to those reported for the adsorption of surfactants. These plots show at least two well defined adsorption steps (see section 3.3), which could not be fitted to the Freundlich or Langmuir equations.

\subsection{The derivation of the equation of multi-step isotherm}

The aim of the present section is to describe these isotherms by a suitable equation because the steps received little attention in the adsorption studies so far.

In the system reaction (5) is supposed:

$$
S+n \times A=S A_{n}
$$


S: empty sites of the soil surface, A: solute, $\mathrm{SA}_{n}$ : surface complex, $n \geq 1$ : a non-integer number representing the average degree of association of the solute molecules.

The equilibrium constant $(K)$ of the reaction:

$$
K=\frac{\left[S A_{n}\right]}{[S] \cdot[A]^{n}}
$$

where $[S],[A],\left[S A_{n}\right]$ are the equilibrium concentrations of $S, A$ and $S_{n}$, respectively.

The available total concentration of the surface sites $[S]_{\mathrm{T}}$ is given by the mass balance equation (7), and $[S]$ can be substituted:

$$
\begin{aligned}
& {[S]_{T}=[S]+\left[S A_{n}\right]} \\
& {[S]=[S]_{T}-\left[S A_{n}\right]}
\end{aligned}
$$

After the substitution of [S] the value of $K$ can be given by equation (9):

$$
\begin{gathered}
K=\frac{\left[S A_{n}\right]}{\left([S]_{T}-\left[S A_{n}\right]\right) \cdot[A]^{n}} \\
{\left[S A_{n}\right]=\frac{[S]_{T} \cdot K \cdot[A]^{n}}{1+K \cdot[A]^{n}}} \\
q=\frac{q_{T} \cdot K \cdot[A]^{n}}{1+K \cdot[A]^{n}}
\end{gathered}
$$

where $q$ and $q_{T}$ are the surface concentrations of $\left[S A_{n}\right] /$ mass adsorbent and $[S]_{\mathrm{T}} /$ mass adsorbent, respectively.

If associates form above a certain concentration limit of the solute, the concentration variable $[A]$ is replaced by the following relationship:

$$
[A]=\frac{c-b+|c-b|}{2}
$$

$c$ : controlled value of the equilibrium concentration of solute, $b$ : critical concentration limit of associates.

If $b=0$ the control variable is given by the concentration of the non-associated solute $(\mathrm{c}=$ $[A])$ and associates can be formed only on the surface. If $b>0$ associates can be formed either on the surface or in the solution and the concentration of these associates appears in equation (13). Its rearrangement results in equation (14) describing one step of the isotherm.

$$
q=\frac{q_{T} \cdot K \cdot\left(\frac{c-b+|c-b|}{2}\right)^{n}}{1+K \cdot\left(\frac{c-b+|c-b|}{2}\right)^{n}}
$$




$$
q=\frac{q_{T} \cdot K \cdot(c-b+|c-b|)^{n}}{2^{n}+K \cdot(c-b+|c-b|)^{n}}
$$

Similarly to the so-called distributed reactivity model which allows the addition of various isotherm equations (Weber et al., 1992) the multi-step isotherm is calculated as the sum of the equation of the $i$ th steps:

$$
q=\sum_{i=1}^{s}\left\{\frac{q_{T_{i}} \cdot K_{i} \cdot\left(c-b_{i}+\left|c-b_{i}\right|\right)^{n_{i}}}{2^{n_{i}}+K_{i} \cdot\left(c-b_{i}+\left|c-b_{i}\right|\right)^{n_{i}}}\right\}
$$

where $q$ means the specific adsorbed amount, $s$ is the number of steps of the isotherm, $q_{T i}$ and $K_{i}$ are the adsorption capacity and the equilibrium constant, while $b_{i}$ and $n_{i}$ are the concentration limit and the average degree of association relevant to the $i$ th step of the curve.

\subsection{Application of multi-step isotherm equation for the adsorption of certain herbicides on soils and its components}

The adsorption properties of those compounds were studied which proved to be stable under conditions being appropriate in static equilibrium experiments. Equation (15) was used to evaluate all of the isotherms. Parameters characteristic for the adsorption curves were calculated by using the nonlinear least square curve fitting procedure of the "Origin" scientific graphing and analysis software.

The adsorption isotherms of chloroacetanilide type herbicides on soils and quartz are shown in Fig. 11. a and b. The two steps of the curves can be clearly seen, and fitting was successful.

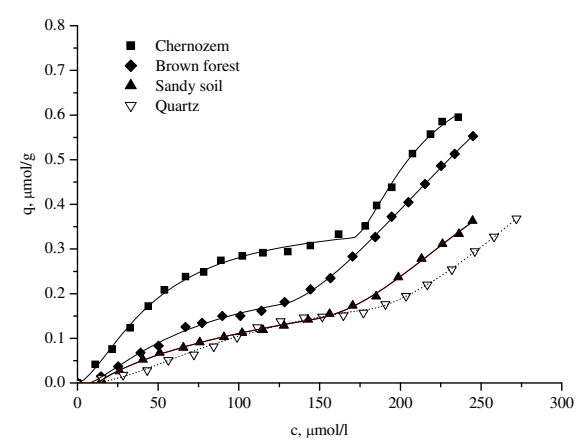

a. Adsorption of acetochlor, $\mathrm{pH}=7$

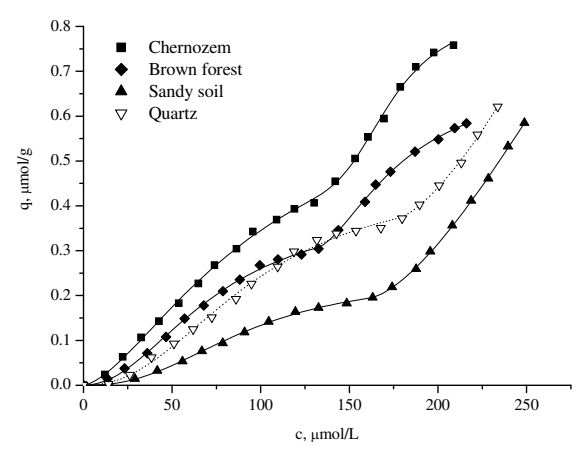

b. Adsorption of propisochlor, $\mathrm{pH}=7$

Fig. 11. Adsorption of acetochlor (1) and propisochlor (2) on different soils and quartz

The mechanism of the adsorption is very similar in the case of these compounds. More propisochlor is bounded by the soils as well as by quartz than acetochlor. The main force of the adsorption is the hydrophobic interaction. 


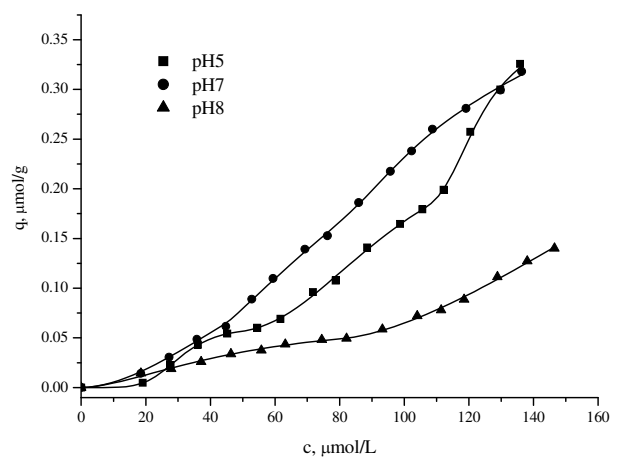

Fig. 12. Adsorption of isoproturon (5) on quartz at different $\mathrm{pH}$ values

The adsorption of isoproturon on quartz is introduced here (Fig. 12). The static equilibrium experiments were carried out at different $\mathrm{pH}$ values. The points were fitted only once by two- $(\mathrm{pH} 8)$ and twice by three-step isotherm equation. Since quartz has neutral siloxane surface that functions as a very weak Lewis base (Johnston \& Tombácz, 2002) under basic conditions the possibly negatively charged isoproturon is adsorbed in lower amounts than at neutral as well as at acidic $\mathrm{pH}$ where the adsorption must be governed by hydrophobic interaction as it was found at chloroacetanilides, too.

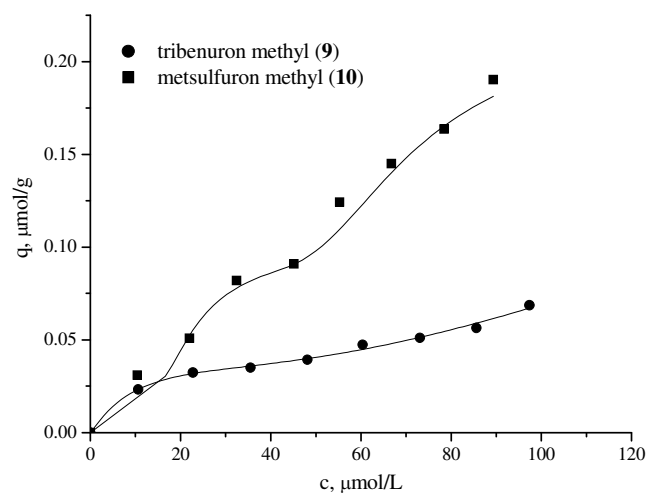

Fig. 13. Adsorption of two sulfonylurea herbicides on chernozem, $\mathrm{pH}=8.3$

Since tribenuron methyl proved to be a rather instable compound under acidic conditions its adsorption studies can give us exact results only at $\mathrm{pH} \geq 7$. Fig. 13 shows the isotherm of two sulfonylurea herbicides (tribenuron methyl and metsulfuron methyl) on chernozem. The $\mathrm{pH}$ of the liquid phase was equal to that of the soil. Metsulfuron methyl (10) has three steps of isotherm and adsorbs in higher amounts on chernozem than the tribenuron methyl (9) having a two-step graph. The structure of $\mathbf{1 0}$ results in a more stabile and less polar compound than $\mathbf{9}$, and the hydrophobic interaction works more effectively leading to more extent adsorption. 


\section{Buffering of pesticide by soil}

The soil has a very important function that is the buffering ability. It means that the soil can adsorb some pesticide as contaminant but it also means if the concentration in the soil solution decreases the pesticides can go to the liquid phase by desorption.

In the literature of soil science and agricultural chemistry the term "buffer capacity" is used mainly for the phosphorus availability and pollution problems. This is the reason that the estimation of the pesticide buffering ability of soils starts here with the equations applied for the better known soil-P system.

The buffer capacity is measured either from the adsorption or from the desorption isotherms and the equilibrium buffer capacity function $B$ is calculable as (16):

$$
B=\frac{\partial q}{\partial c}
$$

The value $B$ can also be described in the following function of the equilibrium concentration specifically in the case of the Langmuir isotherm (Rattan, 2005):

$$
B=\frac{A}{(1+k \cdot c)}
$$

The buffer capacity of the soil-P system can be calculated by means of the phosphorus adsorption isotherm. As a result of the differentiation of the adsorption equation, the equilibrium buffer capacity at any concentration could be calculated as:

$$
B=\frac{d P_{a d s}}{d c}=\frac{1}{3} \cdot \frac{k}{\sqrt[3]{c^{2}}}
$$

It can be assumed that the adsorption reduces exponentially according to the Freundlich isotherm with $n=1 / 3$ exponent.

The advantage of using $Q / I$ relationships $(Q$ : quantity factor - nutrient $(P)$ in the solid phase, $I$ : intensity factor - nutrient $(\mathrm{P})$ in the soil solution) is that they allow the prediction of both $\mathrm{P}$ retention and release in soils (Kpomblekou \& Tabatabai, 1997). The P-buffering capacity of a soil is its ability to resist a change in the P concentration of the solution phase. Phosphorus-buffering capacities of soils can be related to both plant nutrition and environmental pollution. The $Q / I$ model can be applied to either adsorption or desorption experiments (Yaobing \& Michael, 2000). Results showed that $Q / I$ parameters (intercept labile $\mathrm{P}, a$; equilibrium buffering capacity, $B$; and equilibrium $\mathrm{P}$ concentration, EPC) varied significantly between and within sites for the cropping systems studied.

As it is detailed above (see section 3.) the adsorption of herbicides as solutes can not be exactly described neither by simple Langmuir nor by Freundlich equation because these compounds resulted in two- or multi-step isotherms on soils and quartz. Using these isotherms (see equation (15)) the equilibrium buffering capacity $(B)$ was calculated by the derivative function (18):

$$
B=\frac{\partial}{\partial c}\left\{\sum_{i=1}^{s}\left\{\frac{q_{T_{i}} \cdot K_{i} \cdot\left[\left(c-b_{i}\right)+a b s\left(c-b_{i}\right)\right]^{n_{i}}}{2^{n_{i}}+K_{i} \cdot\left[\left(c-b_{i}\right)+a b s\left(c-b_{i}\right)\right]^{n_{i}}}\right\}\right\}
$$


The model parameters $\left(q_{T i}, K_{i}, b_{i}\right.$ and $\left.n_{i}\right)$ were determined by non-linear regression using sequential simplex optimization.

The mechanical calculation of the derivative of function (18) is impossible because of the break point of abs function. We know, however, that the abs function is just needed due to negative $(c-b)$ data which are not taken into account. It means we can make the derivative function as the sum of single Langmuir isotherms in every $x$ region. Therefore the following function can be applied as the equilibrium buffering capacity of multi-step adsorption isotherms:

$$
B=\sum_{i=1}^{s}\left\{\frac{2^{n_{i}} \cdot q_{T_{i}} \cdot K_{i} \cdot n_{i} \cdot\left[\left(c-b_{i}\right)+a b s\left(c-b_{i}\right)\right]^{n_{i}-1}}{\left\{2^{n_{i}}+K_{i} \cdot\left[\left(c-b_{i}\right)+a b s\left(c-b_{i}\right)\right]^{n_{i}}\right\}^{2}}\right\}
$$

Before the interpretation of the calculation of equilibrium buffering capacity of the soil the adsorption isotherms of some pesticides are shown in Figure 14.

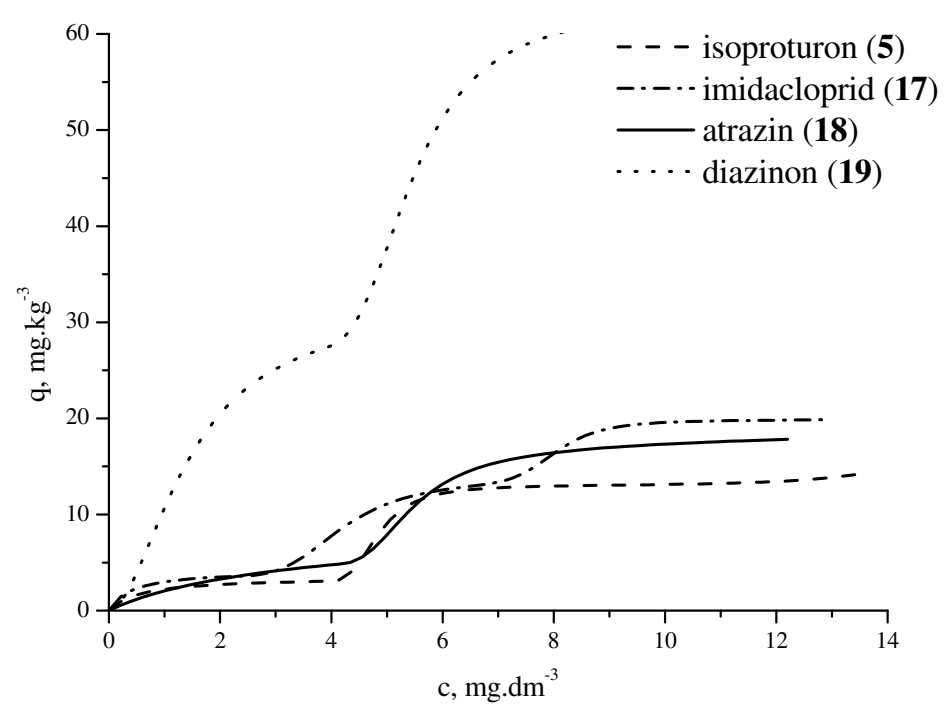

Fig. 14. Adsorption of the investigated pesticides on soil

$\begin{array}{lllllllllllll}\text { Sign } & \mathbf{q}_{\mathbf{T}_{\mathbf{1}}} & \mathbf{q}_{\mathrm{T}_{\mathbf{2}}} & \mathbf{q}_{\mathbf{T}_{\mathbf{3}}} & \mathbf{K}_{\mathbf{1}} & \mathbf{K}_{\mathbf{2}} & \mathbf{K}_{\mathbf{3}} & \mathbf{b}_{\mathbf{1}} & \mathbf{b}_{\mathbf{2}} & \mathbf{b}_{\mathbf{3}} & \mathbf{n}_{\mathbf{1}} & \mathbf{n}_{\mathbf{2}} & \mathbf{n}_{\mathbf{3}} \\ \mathbf{5} & 9.29 & 9.93 & 4.42 & 0.30 & 3.79 & 1.47 & 0 & 4.57 & 13.16 & 0.45 & 0.55 & 3.11 \\ \mathbf{1 7} & 31.73 & 31.89 & 0.00 & 0.51 & 0.28 & 1.00 & 0 & 3.86 & 1.00 & 1.84 & 2.67 & 1.00 \\ \mathbf{1 8} & 9.26 & 10.97 & 0.00 & 0.28 & 0.49 & 1.00 & 0 & 4.16 & 1.00 & 0.95 & 2.46 & 1.00 \\ \mathbf{1 9} & 4.22 & 9.82 & 6.01 & 2.41 & 0.14 & 0.01 & 0 & 2.33 & 5.67 & 1.00 & 3.00 & 6.00\end{array}$

Table 4 . The fitted parameters of the equilibrium buffering capacity data $\left(R^{2} \geq 0.9960\right)$ 
Using the given parameters the equilibrium buffering capacity function was calculated but the larger error of derivative function was fitted on the differentiate data of the original measurement result.

We calculated the new parameters generally (these values are not exactly equal to the original sorption isotherm parameters due to the new fitted weighting points) which are summarized in Table 4.

Calculated functions are shown in Figure 15 where very big differences can be seen in the $B$ values at relatively small equilibrium concentration differences. This phenomenon seems to be almost a periodical change in the case of some compounds.

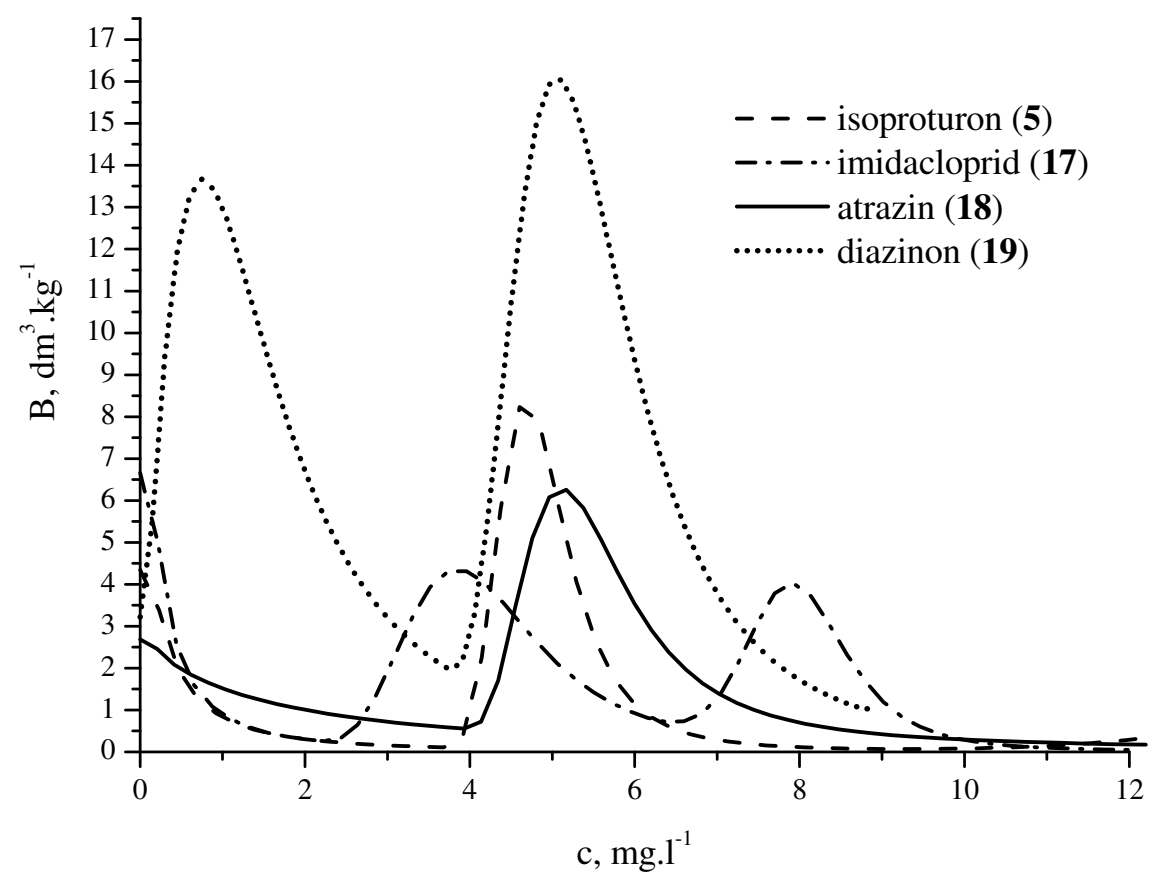

Fig. 15. Equilibrium buffering capacity functions of different pesticides

\subsection{An example: The buffering of isoproturon by soil}

Adsorption of isoproturon (5) on the soil resulted in three steps of isotherm. In this case the adsorption is described by equation (20) while the buffering capacity by equation (21).

$$
q=\frac{\left[q_{T_{1}} \cdot K_{1} \cdot c\right]^{n_{1}}}{\left[1+K_{1} \cdot c\right]^{n_{2}}}+\frac{q_{T_{2}} \cdot K_{2} \cdot\left[\left(c-b_{2}\right)+a b s\left(c-b_{2}\right)\right]^{n_{2}}}{2^{n_{2}}+K_{2} \cdot\left[\left(c-b_{2}\right)+a b s\left(c-b_{2}\right)\right]^{n_{2}}}+\frac{q_{T_{3}} \cdot K_{3} \cdot\left[\left(c-b_{3}\right)+a b s\left(c-b_{3}\right)\right]^{n_{3}}}{2^{n_{3}}+K_{3} \cdot\left[\left(c-b_{3}\right)+a b s\left(c-b_{3}\right)\right]^{n_{3}}}
$$


$B=\frac{q_{T_{1}} \cdot K_{1} \cdot n_{1} \cdot c^{n_{1}-1}}{\left\{1+K_{1} \cdot[c]^{n_{1}}\right\}^{2}}+\frac{2^{n_{2}} \cdot q_{T_{2}} \cdot K_{2} \cdot n_{2} \cdot\left[\left(c-b_{2}\right)+a b s\left(c-b_{2}\right)\right]^{n_{2}-1}}{\left\{2^{n_{2}}+K_{2} \cdot\left[\left(c-b_{2}\right)+a b s\left(c-b_{2}\right)\right]^{n_{2}}\right\}^{2}}+\frac{2^{n_{3}} \cdot q_{T_{3}} \cdot K_{3} \cdot n_{3} \cdot\left[\left(c-b_{3}\right)+a b s\left(c-b_{3}\right)\right]^{n_{3}-1}}{\left\{2^{n_{3}}+K_{3} \cdot\left[\left(c-b_{3}\right)+a b s\left(c-b_{3}\right)\right]^{n_{3}}\right\}^{2}}$

After substitution of calculated parameters, we can write the equation of the isoproturon adsorption and buffering capacity of examined soil samples as follows (see equation (22) and (23):

$$
q=\frac{[9.29 \cdot 0.3 \cdot c]^{0.45}}{[1+0.3 \cdot c]^{0.45}}+\frac{9.93 \cdot 3.79 \cdot[(c-3.57)+a b s(c-3.57)]^{0.55}}{2^{0.55}+3.79 \cdot[(c-3.57)+a b s(c-3.57)]^{0.55}}+\frac{4.42 \cdot 1.47 \cdot[(c-13.16)+a b s(c-13.16)]^{3.11}}{2^{3.11}+1.47 \cdot[(c-13.16)+a b s(c-13.16)]^{3.11}}
$$

$$
B=\frac{9.29 \cdot 0.3 \cdot 0.45 \cdot c^{-0.55}}{\left\{1+0.3 \cdot[c]^{0.45_{i}}\right\}^{2}}+\frac{2^{0.55} \cdot 9.93 \cdot 3.79 \cdot 0.55 \cdot[(c-3.57)+a b s(c-3.57)]^{-0.45}}{\left\{2^{-0.45} \cdot 3.79 \cdot[(c-3.57)+a b s(c-3.57)]^{0.55}\right\}^{2}}+\frac{2^{3.11} \cdot 4.42 \cdot 1.47 \cdot 3.11 \cdot[(c-13.16)+a b s(c-13.16)]^{2.11}}{\left\{2^{3.11}+1.47 \cdot[(c-13.16)+a b s(c-13.16)]^{3.11}\right\}^{2}}
$$

Figure 16 shows the graph of equation (23) emphasizing the special change of $B$ value as a function of the equilibrium concentration.

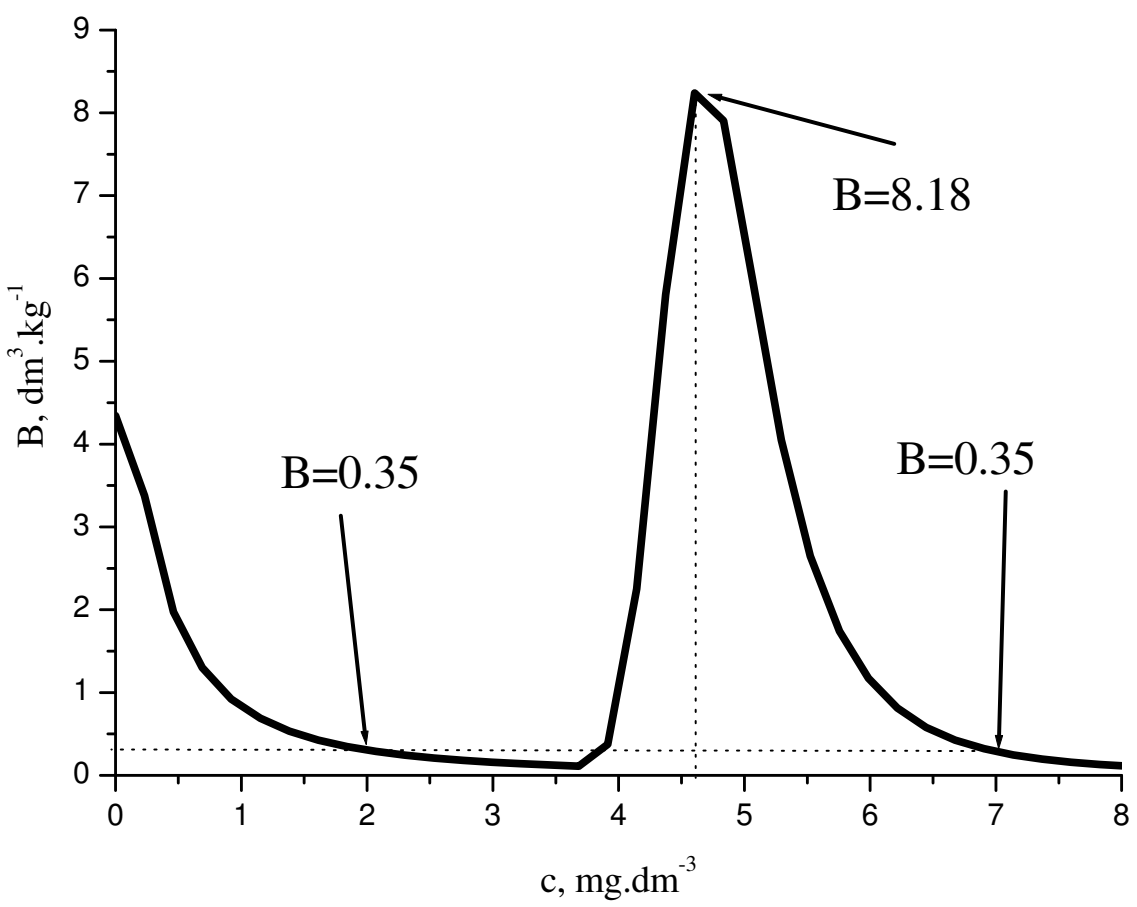

Fig. 16. Equilibrium buffering capacity function of isoproturon 
The adsorption isotherm is shown in Figure 17 with some lines for better understanding. The 0.1 size interval of $c$ is marked three times at very important values. The dotted lines show the adsorbed amount intervals connected to the marked equilibrium concentrations. In the $B$ function one maximum and two minimum points can be found (Fig. 16). At the low equilibrium concentration the adsorbed amount of pesticide increased significantly. It means that the slope of the curve $(B)$ is relatively high. Than the surface concentration is increasing and the system is approximating the surface saturation, while the slope $(B)$ is decreasing. The $B$ value reaches its minimum when the surface is almost saturated: in this area the slope of the adsorbed amount function is almost zero ( $c$ is approx. $3.5 \mathrm{mg} . \mathrm{dm}^{-3}$ ). Than the second layer is forming, and the surface concentration will be zero again. New empty sites are present meaning a new type of surface. The adsorbed amount is increasing in function of equilibrium concentration. When the new small adsorbed regions are evolved, the slope of the curve reaches its maximal value: $B$ has its maximum at $4.5 \mathrm{mg} . \mathrm{dm}^{-1}$ equilibrium concentration. After this point the process explained above takes place again: the surface is saturating, and the $B$ value is decreasing.

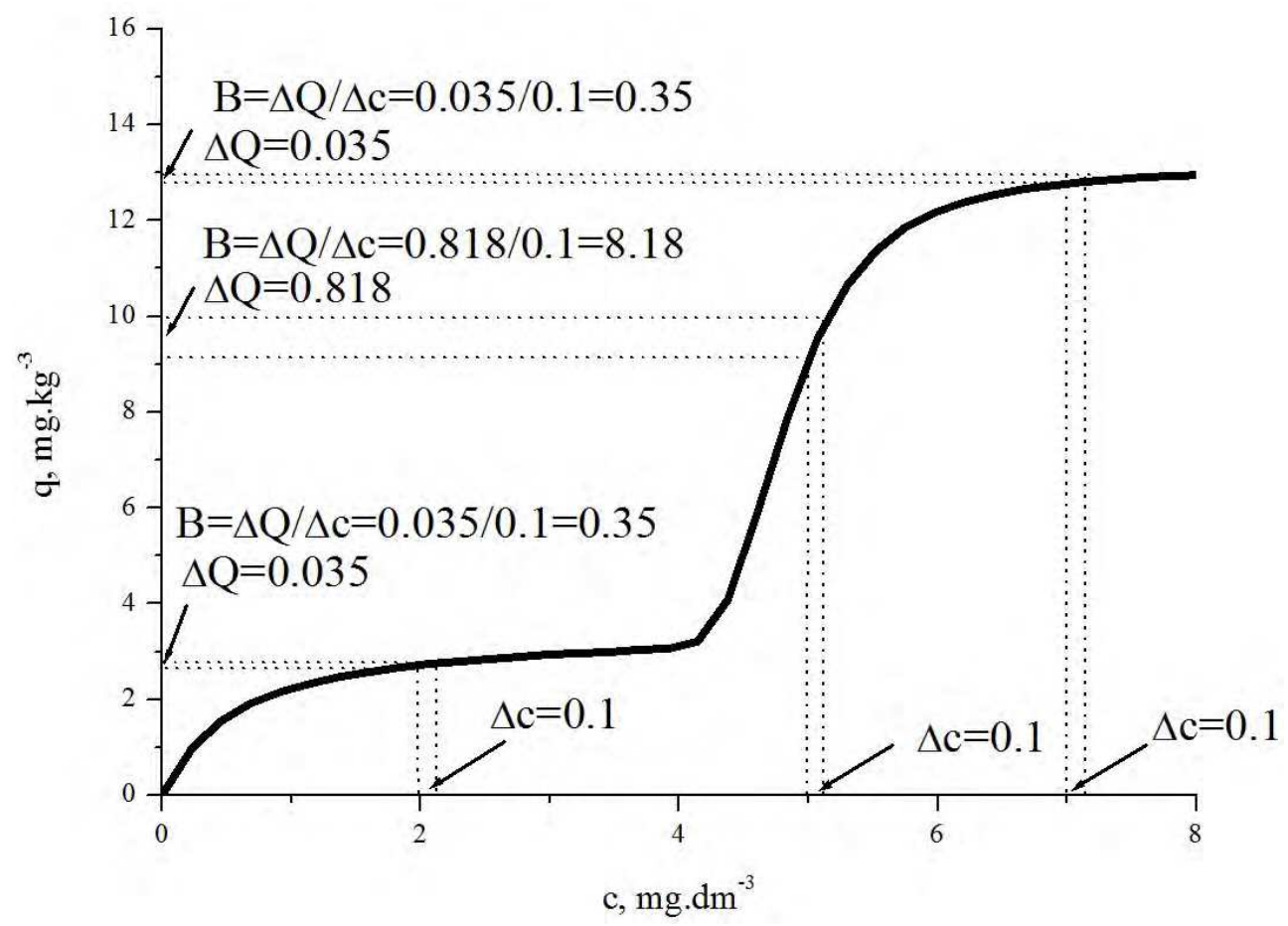

Fig. 17. The explanation of equilibrium buffering capacity function of isoproturon

The parameters and $B$ can be used for calculating of the equilibrium concentration of a contaminated soil while the total amount of a given compound can be calculated from its concentration measured. But this is more complicated, it needs some additional calculations. 
If we know the water content of the soil we can give the ratio of adsorbed and dissolved amount of the investigated compound on the basis of the buffering capacity. In the analytical and monitoring practice the change of the concentration in the liquid phase is measured, and it is generally concluded that this is proportional to the changing in the extent of pollution. According to our research this is not true. The suggested calculation method is detailed below step by step.

In this example the amount of the pesticide is present in one unit $(1 \mathrm{~kg})$ solid phase, and also one unit $\left(1 \mathrm{dm}^{3}\right)$ liquid phase. The ratio of solid/liquid phase has to be calculated in the case of known water content of the soil. If the water content $\Theta$ is given in $\mathrm{dm}^{3} \cdot \mathrm{dm}^{-3}$, the volume of solid phase is $1-\Theta$ in $\mathrm{dm}^{3} \cdot \mathrm{dm}^{-3}$. In this case the following relationship can be written:

$$
Q=\frac{1-\Theta}{\Theta} \cdot q
$$

where $Q$ is the extent of pollution in solid phase of wet soil, mg.kg-1, $q$ is extent of pollution in clear solid phase of soil (specific adsorbed amount of pollutant), mg.kg-1, $\Theta$ is the water content of the soil, $\mathrm{dm}^{3} \cdot \mathrm{dm}^{-3}$.

The changing of the extent of pollution in solid phase at given water content of the soil can be calculated by the application of equation (24).

$$
d Q=\frac{1-\Theta}{\Theta} \cdot B \cdot d c
$$

where $d Q$ is he change of the extent of pollution in solid phase, mg.kg-1, $d c$ is the change of the concentration in the solution, mg.dm-3,$B$ is the equilibrium buffering capacity, $\mathrm{dm}^{3} \cdot \mathrm{kg}^{-1}$. In order to calculate the total amount of the compound in milligrams in the soil we must summarize its amount in the solid as well as in the liquid phase.

$$
d Q=\frac{1-\Theta}{\Theta} \cdot V_{\text {soil }} \cdot \rho_{\text {soil }} \cdot B \cdot d c+\frac{\Theta}{1-\Theta} \cdot V_{\text {soil }} \cdot d c
$$

where $V_{\text {soil }}$ is the total volume of examined soil $\mathrm{dm}^{3}, \rho_{\text {soil }}$ is density of solid phase of soil, mg.dm ${ }^{-3}$.

In the present example let us assume that we have got one hectare of soil with $25 \mathrm{~cm}$ plugged layer, and we calculate total amount of adsorbed material in kilograms.

$$
d Q=10^{-6} \cdot\left(\frac{1-\Theta}{\Theta} \cdot \rho_{\text {soil }} \cdot B+\frac{\Theta}{1-\Theta}\right) \cdot V_{\text {soil }} \cdot d c
$$

where $\rho_{\text {soil }}$ is the density of solid phase, about $2.6 \mathrm{~kg} . \mathrm{dm}^{-3} ; V_{\text {soil }}$ is the volume of soil, in this case $2500000 \mathrm{dm}^{3} ; d Q$ is the change of the extent of pollution in the given soil area, $\mathrm{kg}$.

Substituting the derived function into $B$ we can calculate the changing buffering effect of the soil in the function of changing equilibrium concentration of the given pesticide. In order to make an approximate calculation, we do not need to use the total complicated function. How we can decide which part should be used from this sum? We have to compare the equilibrium concentration with $b_{i}$ parameters and we have to choose that part of sum, where $b_{i}$ is less than the equilibrium concentration, but $b_{\mathrm{i}}+1$ is bigger than $c$. 
If the equilibrium concentration is less than $3.5 \mathrm{mg}^{-\mathrm{dm}^{-3}}$ the substitution of the known data into equation (27) results in equation (28):

$$
d Q=10^{-6} \cdot\left(\frac{1-0.2}{0.2} \cdot 2.6 \cdot \frac{9.29 \cdot 0.3 \cdot 0.45 \cdot c^{-0.55}}{\left\{1+0.3 \cdot[c]^{0.45}\right\}^{2}}+\frac{0.2}{1-0.2}\right) \cdot 2500000 \cdot d c
$$

where $\rho_{\text {soil }}$ is the density of solid phase, about $2.6 \mathrm{~kg} . \mathrm{dm}^{-3} ; V_{\text {soil }}$ is the volume of soil, in this case $2500000 \mathrm{dm}^{3} ; \Theta$ is the water content of the soil, $\mathrm{dm}^{3} \cdot \mathrm{dm}^{-3}$, in this case 0.2 .

If the value of $c$ is: $13.5 \mathrm{mg} . \mathrm{dm}^{-3}>c>3.5 \mathrm{mg} \cdot \mathrm{dm}^{-3}$, the substitution of the known data into equation (27) results in equation (29):

$$
d Q=10^{-6} \cdot\left(\frac{1-0.2}{0.2} \cdot 2.6 \cdot \frac{2^{0.55} \cdot 9.93 \cdot 3.79 \cdot 0.55 \cdot[(c-3.57)+a b s(c-3.57)]^{-0.45}}{\left\{2^{-0.45} \cdot 3.79 \cdot[(c-3.57)+a b s(c-3.57)]^{0.55}\right\}^{2}}+\frac{0.2}{1-0.2}\right) \cdot 2500000 \cdot d c
$$

The calculations above emphasize how big difference can be calculated depending on the equilibrium concentration. It is the reason for using the whole buffering capacity equation and the soil parameters given in equation 28.

Based on the isoproturon curve (Fig. 17.) it can be seen if the equilibrium solution concentration increased from $2 \mathrm{mg} . \mathrm{dm}^{-3}$ to $2.1 \mathrm{mg} \cdot \mathrm{dm}^{-3}, B$ is $0.35 \mathrm{dm}^{3} \cdot \mathrm{kg}^{-1}$. The change in the total isoproturon content is $0.1 \mathrm{~kg}$. If the equilibrium solution concentration is increasing from $4.5 \mathrm{mg} . \mathrm{dm}^{-3}$ to $4.6 \mathrm{mg} . \mathrm{dm}^{-3}$ under the same conditions (water content and isoproturon buffer function), $B$ is $8.18 \mathrm{dm}^{3} \cdot \mathrm{kg}^{-1}$. If $c$ changes from $7 \mathrm{mg} \cdot \mathrm{dm}^{-3}$ to $7.1 \mathrm{mg} . \mathrm{dm}^{-3}$, the value of $B$ is $0.35 \mathrm{dm}^{3} \cdot \mathrm{kg}^{-1}$ again. The change in total isoproturon content is $21 \mathrm{~kg}$.

In opposite point of view, for example let's suppose $20 \mathrm{~kg}$.ha-1 isoproturon added into the soil, presumably for plant protection activity. If the original equilibrium solution concentration was $2 \mathrm{mg} . \mathrm{dm}^{-3}$ it is increasing by $2 \mathrm{mg}^{-\mathrm{dm}^{-3}}$ and results in $100 \%$ arising. If the original equilibrium solution concentration was $4.5 \mathrm{mg} \cdot \mathrm{dm}^{-3}$, the increasing is $0.1 \mathrm{mg} . \mathrm{dm}^{-3}$ which means just $2 \%$. In the case of $7 \mathrm{mg} \cdot \mathrm{dm}^{-3}$ of original equilibrium solution concentration the increasing is $2 \mathrm{mg} \cdot \mathrm{dm}^{-3}$ ( $35 \%$ arising).

\section{Conclusion}

The chloroacetanilide type herbicides acetochlor and propisochlor proved to be rather stable compounds under the given conditions. Degradation can occur due to the presence of soil microorganisms. Tribenuron methyl being a sulfonyl urea type compound is stable only under basic conditions and it is decomposed in acidic soils fast. Three degradation products were identified by GC-MS: two of them are formed through acidic hydrolysis and the third newly investigated compound is attributable to the presence of organic matter content of the soil (e.g. humic substances). The structure of metsulfuron methyl is very similar, however, its breakdown is slow. Isoproturon is a rather persistent compound. Its degradation hardly depends on $\mathrm{pH}$ but it is faster in the presence of the soil. Two degradation products were identified which can prove the photo catalytic effect of humic substances.

New equation has been derived by making use of the usual mass balance and equilibrium relationships of the adsorption and by considering the possibility of the formation of 
associates of the solute molecules. The characteristic model parameters of each step of the adsorption isotherm were estimated for the studied systems by a non-linear least square regression.

Its applicability is proved by the fitting of the isotherms of herbicides having different structures. The calculated curves fit well to the experimentally obtained multi-step isotherms. The parameters of the model can be used for the characterization of the pesticide-soil interactions. On the basis of the new equation formulas were derived to calculate the equilibrium buffering capacity $(B)$ of soil. These buffer capacity equations show special curves with one or more peaks. The measured and fitted values were recalculated by using real soil parameters. These results indicate that we must redefine our original contamination assessment methods in order to avoid even a magnitude error. Not only the equilibrium solution concentration measurement is very important for assessing the real amount of contaminants but also the equilibrium buffering capacity $(B)$ function has to be used.

\section{Acknowledgment}

The authors gratefully acknowledge their former students - Tímea Ertli, Zsófia Lengyel and Csaba Érsek - for their valuable work.

This chapter was written by the support of the Hungarian National Development Agency (TECH-09-A4-2009-0133, BDREVAM2 project) as well as of the European Union and the European Social Foundation in the frame of the New Hungary Development Plan (TÁMOP4.2.1.B-10/2/KONV-2010-0001 projects).

\section{References}

McBride, M. B. (1994). Environmental Chemistry of Soils, p. 342, Oxford University Press, ISBN 0-19-507011-9, New York, USA

Carmo, A. M.; Hundal, L. S. \& Thompson, M. L. (2000). Sorption of hydrophobic organic compounds by soil materials: Application of unit equivalent Freundlich coefficients. Environ. Sci. Technol. Vol.34, No.20, pp. 4363-4369

Clunie, J. S.; Ingram, B. T. (1983). Adsorption of nonionic surfactants. In: Adsorption from Solution at the Solid/Liquid Interface. Parfitt, G. D.; Rochester, C. H. (Eds.), pp. 105 152, ISBN 0125449801, Academic Press, London, UK

Ferenczi, J. (1998). Field studies of the behavior of pesticides in the catchment area of the Lake Balaton (in Hungarian). PhD Theses. Pannon University of Agricultural Sciences, Keszthely, Hungary

Gerecke, A. C.; Canonica, S.; Müller, S. R.; Schärer, M. \& Schwarzenbach, R. P. (2001). Quantification of dissolved natural organic matter (DOM) mediated phototransformation of phenylurea herbicides in lakes, Environ. Sci. Technol. Vol.35, No.19, pp. 3915-3923

Johnston, C. T.; Tombácz, E (2002). Surface Chemistry of Soil Minerals. Chapter 2 In: Soil Mineralogy with Environmental Applications, SSSA Book Ser 7, SSSA, Dixon, J.; Schulze, D. (Eds), pp. 37-67, Soil Science Society of America, ISBN 0-89118-839-8, Madison, USA 
Jönsson, B.; Lindman, B.; Holmberg, K. \& Kronberg,B. (1998). Surfactants and Polymers in Aqueous Solution, (a) pp. 265-294, (b) p. 37, John Wiley and Sons, ISBN 0471-974226, Chichester, UK

Klein, M.; Müller, M.; Dust, M.; Görlitz, G.; Gottesbüren, B.; Hassink, J.; Kloskowski, R.; Kubiak, R.; Resseler, H.; Schäfer, H.; Stein, B. \& Vereecken, H. (1997). Validation of the pesticide leaching model PELMO using lysimeter studies performed for registration. Chemosphere Vol.35, No.11, pp. 2563-2587

Kpomblekou-A K.; Tabatabai M. A. (1997). Effect of cropping systems on quantity/intensity relationships of soil phosphorus. Soil Sci. Vol.162, No.1, pp. 56-68

Konda, L. N. \& Pasztor, Z. (2001). Environmental distribution of acetochlor, atrazine, chlorpyrifos, and propisochlor under Weld conditions. J Agr Food Chem, Vol.49, No.8, pp. 3859-3863

Kovács, B. (1998). Environmental applications of contaminant transport models (in Hungarian). PhD Theses. University of Miskolc, Miskolc, Hungary.

Mader, B. T.; Uwe-Gross, K. \& Eisenreich, S. (1997). Sorption of nonionic, hydrophobic organic chemicals to mineral surfaces. Environ. Sci. Technol. Vol.31, No.4, pp. 10791086

Pierzynski, G. M.; Sims, J. T. \& Vance, G. F. (1994). Soils and Environmental Quality, pp. 187-190, Lewis Publishers, ISBN 0-87371-680-9, Boca Raton, USA

Rattan L. (Ed.), (2005). Encyclopedia of Soil Science, Taylor \& Francis Group LLC, ISBN 084933-830-1, New York, USA

Roberts, T. (Ed.), (1998). Metabolic Pathways of Agrochemicals, Part 1: Herbicides and Plant Growth Regulators, (a) pp. 183-187, (b) p. 706, (c) pp. 735-739, (d) pp. 451-473, The Royal Society of Chemistry, ISBN 0-85404-494-9, Cambridge, UK

Samiullah, Y. (1990). Prediction of the Environmental Fate of Chemicals. Elsevier Science Publishers Ltd., pp. 110-112, ISBN 1-85166-450-5, Barking, UK

Skibniewska, K. A.; Guziur, J.; Grzybowski, M. \& Szarek, J. (2003). DDT in soil of pesticide tomb and surrounding ecosystems, Proceedings of the 10 th Symposium on Analytical and Environmental Problems, pp. 27-31, ISBN 963212867 2, SZAB, Szeged, Hungary, September 29, 2003

Voice, T. C.; Weber Jr., W. J. (1983). Sorption of hydrophobic compounds by sediments, soils and suspended solids - I. Water Res. Vol.17, No.10, pp. 1433-1441

Wang, S. L.; Liu F. M.; Jin S. H. \& Jiang, S. R. (2007) Dissipation of propisochlor and residue analysis in rice, soil and water under field conditions, Food Control, Vol.18, No.6, pp. 731-735

Weber, W. J. Jr.; McGinley, P. M. \& Katz, L. E. (1991). Sorption phenomena in subsurface systems: concepts, models and effects on contaminant fate and transport. Water Res. Vol.25, No.5, pp. 499-528

Weber, W. J. Jr.; McGinley, P. M. \& Katz, L. E. (1992). Distributed reactivity model for sorption by soils and sediments. Environ. Sci. Technol. Vol.26, No.10, pp. 1955 - 1962

Weber, W. J. Jr.; Voice, T. C.; Pirbazari, M.; Hunt, G. E. \& Ylanoff, D. M. (1983). Sorption of hydrophobic compounds by sediments, soils and suspended solids - II. Water Res. Vol.17, No.10, pp. 1443 - 1452 
Wolt, J. D. (1994). Soil Solution Chemistry, Applications to Environmental Science and Agriculture. John Wiley \& Sons, Inc., p.169, ISBN 0-471-58554-8, New York, USA

Yaobing S. \& Thompson M. L. (2000). Phosphorus Sorption, Desorption, and Buffering Capacity in a Biosolids-Amended Mollisol, Soil Science Society of America Journal Vol.64, pp. 164-169

Zettlemoyer, A. C.; Micale, F. J. (1971). Solution adsorption thermodynamics for organics on surfaces. In: Organic Compounds in Aquatic Environments. Faust, S.D., Hunter, J.V. (Eds.)., pp. 180-181., Marcel Dekker, Inc., ISBN 0824711882, New York., USA 


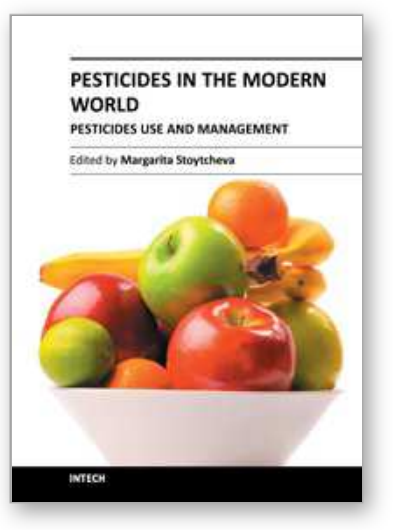

\author{
Pesticides in the Modern World - Pesticides Use and Management \\ Edited by Dr. Margarita Stoytcheva
}

ISBN 978-953-307-459-7

Hard cover, 520 pages

Publisher InTech

Published online 19, October, 2011

Published in print edition October, 2011

This book brings together issues on pesticides and biopesticides use with the related subjects of pesticides management and sustainable development. It contains 24 chapters organized in three sections. The first book section supplies an overview on the current use of pesticides, on the regulatory status, on the levels of contamination, on the pesticides management options, and on some techniques of pesticides application, reporting data collected from all over the world. Second section is devoted to the advances in the evolving field of biopesticides, providing actual information on the regulation of the plant protection products from natural origin in the European Union. It reports data associated with the application of neem pesticides, wood pyrolysis liquids and bacillus-based products. The third book section covers various aspects of pesticides management practices in concert with pesticides degradation and contaminated sites remediation technologies, supporting the environmental sustainability.

\title{
How to reference
}

In order to correctly reference this scholarly work, feel free to copy and paste the following:

Rita Földényi, Imre Czinkota and László Tolner (2011). Pesticide-Soil Interaction, Pesticides in the Modern World - Pesticides Use and Management, Dr. Margarita Stoytcheva (Ed.), ISBN: 978-953-307-459-7, InTech, Available from: http://www.intechopen.com/books/pesticides-in-the-modern-world-pesticides-use-andmanagement/pesticide-soil-interaction

\section{INTECH}

open science | open minds

\section{InTech Europe}

University Campus STeP Ri

Slavka Krautzeka 83/A

51000 Rijeka, Croatia

Phone: +385 (51) 770447

Fax: +385 (51) 686166

www.intechopen.com

\section{InTech China}

Unit 405, Office Block, Hotel Equatorial Shanghai

No.65, Yan An Road (West), Shanghai, 200040, China

中国上海市延安西路65号上海国际贵都大饭店办公楼 405 单元

Phone: +86-21-62489820

Fax: $+86-21-62489821$ 
(C) 2011 The Author(s). Licensee IntechOpen. This is an open access article distributed under the terms of the Creative Commons Attribution 3.0 License, which permits unrestricted use, distribution, and reproduction in any medium, provided the original work is properly cited. 